sob as arcadas escalando depois o mais alto degráu da administracão politica nacional; tambem viu o seu grande zĉlo glorificado e sua grande alma, compreendida por todos, assistindo emocionado a saudação entusiastica da geração academica de 1934, que estremeceu as paredes coloniais do velho templo do Direito.

Julio Maia deixou a Faculdade de Direito de S. Paulo, causando comoçāo a todos os coraçōes que se abriram para guardit-lo cternamente.

Embora, deixando-nos, depois de acostumados a vèr aquele padrão de virtude e de bondacle, traremos sempre na memoria sua imagem querida e no coração uma gratidāo imorredoura.

Arcadas, Novembro de 1934.

\title{
PROMOÇõES POR MEDIAS
}

O professor dr. Waldemar Ferreira, vice-dirotor da Faculdade de Direilo de São Paulo, cm exercicio, dirigiu ao deputado á Camara Federal, professor dr. Alcantara Machado, o telegrama seguinte, que foi lido em sessão, a 21 de Novembro:

"A congregação da Faculdade de Direito de São Paulo, tendo dirigido apelo á Camara dos Deputados para rejeição do projeto de aprovação por médias, solicita eminente colega todo empenho no mesmo sentido. - Dr. Waldemar Ferreira, vice-diretor da Faculdade de Dircito de São Paulo.

Inquirido por um redator do "Diario de São Paulo" acêrca da questão, assim se exprimiu o professor dr. Waldemar Ferreira:

"Baixou tanto o nivel do ensino superior e secundario cm nosso pais, devido ás medidas de desmoralização de um c de outro, provindas das autoridades superiores, emanadas do poder legislativo, que a Segunda Constituinte Republicana tom ou sobre si a missão de impedir o desenvolviniento da avalanche.

Muito de industria, vedou $\circ$ art. 158 da Constituição de 16 de julho de 1934 "a dispensa de concurso de titulos e provas no provimento dos cargos do magisterio oficial, bem como, em qualquer curso, a de provas escolares de habilitação, determinadas em lei ou regulamento".

"Supunha-se, e agora bem se percebe que não sem certa ingenuidade, que estava liquidada, definitivamentc, a enfermidade periodica, e quasi fatal, que em todos os dezembros, se apoderava da mocidade universitaria brasileira. 
Eis que ela reapareceu.

Um desapontamento. Porque as vergonhas desapontam.

Quando se havia ide pensar que, na Camara dos Deputados, se havia de levantar alguem, e principalmente um homem de responhabilidades para com o pais, a propôr a dispensa, este ano, dos exames onais, ou seja de provas escolares de habilitação, determinadas nas leis e nos regulamentos?

Por mais impossivel e inconstitucional que seja, a coisa apareceu e ai está.

Será que os legisladores da segunda republica se igualarão na mesma ignominia dos da primeira republica, degradando o ensino superior no Brasil?"

\section{Ignorancia de estarrecer}

- "Professor universitario, conscio dos meus deveres para com os moços, venho sentinulo, dia a dia, que eles se apresentam, nos cursos superiores, em boa parte, minados por uma ignorancia de estarrecer. Quem se der ao trabalho de examinar as provas escritas parciais verificará. com espanto, que não são poucos os estudantes de curso juridico incapazes de redigir duas frases seguidas sem incorreções gramaticais.

E' doloroso dizê-lo. Sinto-me, porém, na obrigação de denunciar ao país o grande mal das aprovações por decreto e com dispensa das provas de habilitações. Ha, sem duvida, mocos estudiosos e senhores de aprimorada cultura; mas são tão poucos, que merecem eles todas as honrarias"

\section{Efeitos das aprovações por decreto}

Com a mesma energia inicial, o prof. Waldemar Ferreira prosseguiu, dizendo

por médias?

Instituiu-se, em 1930, um premio, na Faculdade de Direito de São Paulo - o premio Carvalho de Mendonça - para ser distribuido, todos os anos, ao melhor aluno de direito comercial. Foi ele, pela primeira vez, distribuido, em 6 de agosto de 1930, ao então estudante José Horacio Meirelles Teixeira. Depois disso, não pôde mais ser conferido. Os exames por decreto e por médias o impediram" 


\section{Um apelo á Camara dos Deputados}

- "Não. Encerremos esta conversa. Ela é daquelas que rerem o coração dos que têm responsabilidades na formação da mocidade brasileira.

Deixemos de falar em coisas tristes.

A Congregação da Faculdade de Direito de São Paulo, ha poucos dias, ao terminar as provas do concurso para professor catedratico de direito romano, resolveu dirigir um apelo á Camara dos Depulados. Parece que ele calou fundo na conciencia nacional. Têm-nos ohegado, de varios pontos do país tantas manifestaçōes de sulidaricdade, que ainda ousamos esperar que a Camara dos Deputados o atenda.

Se isso nāo acontecer, que valha ele como um protesto vibrante e sincero da nossa gloriosa Academia de Direito"

Ao "Estado de S. Paulo" fez o professor dr. Waldemar Ferreira as seguintes declaraçōes, publicadas a 15 de Dezembro de 1934:

\section{Equivocos e confusões}

- Antes de mais nada, convem desfazer uma confusāo acerca do que vem sendo designado pela expressão "promoçāo por médias" Essa confusāo tem servido para alimentar duridas quanto ao sentido da campanha sustentada pelos responsaveis pelo ensino superior contra as inovações agora em roga. Tal expressão foi mal escolhida e porisso significou coisa muito diversa da que deveria designar. Ninguem é contra a promoção por médias. .

- Entretanto, observámos, a impressão do publico i a de quc os professores, em geral, são contra esses sistema de promoção...

- Pois, ai está, precisamente, o primeiro equivoco que é preciso desfazer. Pelo sistema de ha muito estabelecido nas faculdades brasileiras, a regra é que os estudantes sejam promovidos por médias. Durante muito tempo o sistema adołado era o de dois exames finais, um escrito e outro oral, concluindo pela aprovação ou reprovação do examinando. Mas atualmente já não é assim. Aqui tem o sr. o regulamento da Faculdade de Direito. Tratando das provas de habilitação do aluno, ele estabeleceu que, para efeito de promoção e de formatura, deverá essa habilitação ser verificadiı por provas parciais e finais. As provas parciais são escritas e as finais são orais. As primeiras realizam-se de 10 a 20 de Junho ? 
de 20 a 30 de Setembro de cada ano. Lma no primeiro, outro no segundo semestre. As provas finais efetuar-se-ão a partir do primeiro dia util de Dezembro.

A cada prova escrita atribue o respectivo examinador uma nota, de zéro a lez, e a metade da soma das notas dessas provas será a média do aluno na respecliva cadeira. Os alunos que, dessas duas provas parciais, tiverem média cinco, no minimo, poderão fazer a prova oral, isto é, a prova final do ano letivo.

Terminados esses exames orais de cada turma, a comissão examinadora, a qual terá a vista as provas escritas, procede ao julgamento, da seguinte forma:

a) cada examinador atribue á prova oral uma nota, de zero a dez, apurando-se a respectiva média;

b) em seguida, tira-se a média final das notas das tres provas, escritas e oral;

c) considera-se reprovado o aluno que tiver media final inferior a cinco;

d) considera-se aprovado simplesmente o aluno que obtiver média final de cinco até seis; plenamente, o que obtiver média final de mais de seis, até nove; com distinção, o que obtiver média final de mais de nove.

Para obtenção da média final, serão compuladas tres notas: a da oral e as das duas provas escritas.

Ai está o que prescreve o regulamento. Isso prova, com evidencia, que na Faculdade de Direito (e o mesmo acontece nos outros institutos universitarios de São Paulo), as promoções e as formaturas dos estudantes se rcalizam, como cu dizia, por médias.

\section{$\mathrm{O}$ que querem os estudantes}

- Mas a impressão do publico é a de que é isso. exatamente, o quc os estudantes estão pleiteando! Pois não se tem dito que o projeto Ribeiro Junqueira visava introduzir em nossas faculdades um regime delas desconhecido?

- Nada disso. Tudo decorre da confusão a que deu lugar a malsinada expressão: "promocão por médias" a que de começo aludi. O que o projeto Ribeiro Junqueira se propôs, exclusivamente, foi dispensar os estudantes de uma daquelas provas - as provas finais, provas orais, que sempre sc realizaram e sempre serviram para a revelação dos mais belos talentos que têm passado pelos nossos cursos academicos. Os estudantes de hoje -. esta é a verdade - não pleiteiam, senão "in nomine" as promoções "por médias" pois, como se viu, é justamente por esse sistema que eles normal- 
mente se promovem de ano em ano. O que pleiteiam é, pura e simplesmente, a supressão das provas finais, tidas como as mais dificeis e que sempre lhes deram um pouquinho mais de trabalho, obrigando-os a voltarem-se um pouco para os livros, do que nem todos gostam muito. E' por isso, sem duvida, que alguns têm qualificado o ensino, que se lhes ministra, de livresco...

\section{Provas escritas e provas orais}

- Acha, então, que deve ser mantida a prova oral? Contra cla argue-se que nem todos os estudantes têm a facilidade da expressão verbal, pelo que é ela uma forma imperfeita de se avaliarem conhecimentos.

- Sim. Deve ser mantida, a-pesar-de sua imperfeição. Impurfeita tambem o é a prova escrita, como imperfeitos serão todos os processos de avaliar conhecimentos humanos, principalmente quando sujeitos a julgamentos humanos. Por isso mesmo é que se juntaram as duas provas: as escritas e as orais. Lns têm maior facilidade de falar, outros de escrever: outros escreven e falam bein, outros nem uma nem outra coisa.

Demais, pelo sistema regulamentar, as notas das provas escritas são dadas a essas provas tais quais e se apresentam aos examinadores, que desconhecem os seus autores.

O julgamento o é da prova em si, não do estudante. O contingente pessoal de cada um entra na prova oral. A assiduidade, as boas liçōes em aula, os trabalhos escolares realizados durante o ano e os dados á publicidade nas revistas academicas, e outros elementos pessoais entram em linha de conta para a nota do exame oral. Tudo, portanto, aconselha que se mantenham os exames orais, principalmente na Faculdade de Direito. Quanto maior numero de provas, melhor.

\section{Provas praticas}

Abordámos, então, a questão das provas praticas, de que tanto se tem falado netses ultimos tempos. A seu respeito, disse-nos o sr. professor Waldemar Ferreira:

- Sem duvida, devem ser adotadas, quando possiveis. Delas tratou João Mendes Junior, em magnifico trabalbo publicado na "Revista da Faculdade de Direito de Sāo Paulo" ao estudar os problemas do ensino do Direito. E assim se exprimiu o saudosissimo mestre : 
"Compreende-se uma prova pratica em Direito Civil e Comercial, realtivamente ás cautelas e formulas dos contratos e testamentos; comprende-se uma prova pratica em Direito Judiciario, relativamente aos atos e termos do processo, assim como ao modo e forma do procedimento; compreende-se uma prova pratica em Medicina Publica, relativamente aos exames de corpo de delito, aos exames de sanidade, assim como a exames físicos e quimicos em caso que afectam a Higiene Publica. Mas é unna vacuidade a prova pratica de Direito Administrativo, relativamente ao movimento dos atos da administração; é outra vacuidade a prova partica de Economia Politica, relativamente aos fenomenos e produção, circulação, distribuição e consumo das riquezas; é outra vacuidade a prova pratica de Direito das Gentes e Diplomacia, relativamente a relações e a conflitos internacionais".

Em tais termos, nada se opõe a que tambem se submetam os estudantes a provas praticas, contra as quais, tudo leva a crêr, êles mesmos se insurgirão, se forem instituidas, como agora fizeram contra as provas orais..

\section{A questão da frequencia}

- E quanto á obrigatoriedade da frequencia ás aulas, contra a qual tambem reclamam os estudantes: deve ser mantida, ou deve ser abolida?

- Sobre esse assunto já tive oportunidade de manifestar-me em informação que, na qualidade de vice-diretor da Faculdade de Dirito, prestei ao sr. secretario da Educação. Tratava-se de um requerimento em que alunos da Faculdade podiam dispensa da obrigação de frequencia, a que legalmente estão sujeitos, para se inscreverem aos exames de 1." época. Nesse requerimento déra o reitor da Universidade, professor dr. Reynaldo Porchat, a seguinte informação:

"Os proprios requerentes reconhecem que o regulamento da Faculdade de Direito, ora em vigor, prescreve a frequencia obrigatoria dos alunos do curso de bacharelado a dois terços das aulas que forem dadas, sob pena de não poderem prestar exames na primeira época. O que requerem êles, é, portanto, contrario ao regulamento.

Nessas condições, os fatos expostos, e as razões em que se apoia o pedido, não autorizam o seu deferimento. São Paulo, 16-10-34. -.. Reynaldo Porchat".

Devendo informar, por meu turno, no mesmo requerimento, eis quais foram as minhas palavras:

"Como muito bem o demonstrou o exmo. sr. reitor da Universidade de São Paulo, não é de deferir-se o pedido formulado por varios alunos da Faculdade de Direito no sentido de serem todos, in- 
distintamente, admitidos á inscrição para as provas finais deste ano letivo em primeira época, não obstante não terem a frequencia minima de dois terços das aulas dadas de cada materia. Nāo é de deferir-se, antes de tudo, pela razão principal e irremovivel de ser contrario á lei. Preceitua, com efeito, o art. 118 do regulamento anexo ao decr. n.' 6.429, de 9 de Maio de 1934, que "não poderá prestar exame final na primeira época (Dezembro) o aluno que não tiver comparecido a dois terços, no minimo, das aulas dadas em cada cadeira, cujo exame pretenda fazer"; e tal preceito se acha repetido no art. 121, paragrafo unico, quando, tratando "das provas de habilitação" refere que "poderão inscrever-se para provas finais símente os alunos que tenham frequencia minima de dois terços das aulas dadas, da respectiva cadeira, e obtido, no minimo, nota cinco na media das provas parciais. Não sendo, por isso, possivel deferir-se o pedido, por contrario a expressos textos de lei; c visto que a lei só se revoga ou derroga por outra lei, caso tambem não é de cogitar-se de nova lei sobre o assunto, pois que lamben se acha êle plena e satisfatoriamente resolvido pela lei em vigor.

\section{Frequencia livre}

O Brasil, tem sido dito em varios tons, é um pais de autodidatas. Estabeleceu-se, sem duvida por essa razão, o sistema da livre frequencia aos cursos juridicos. Nenhum estudante, matriculado na Faculdade de Direito, é obrigado a frequentar-lhe as aulas. Não está sujeito a pena alguma o que não puder ou não quiser seguir-lhe os cursos. Sempre poderá fazer os seus exames e promover-se para os anos seguintes. Sempre foi assim. Não sāo poucos os bachareis formados sem terem frequentado os cursos academicos. Existe, para estes, uma época especial de exames, tradicionalmente. E' a segunda época. Duas, verdadeiramente, são as épocas de exames: a primeira - em Dezembro; e a segunda - na primeira quinzena de Fevereiro. Porque é assim, cuidou a lei, entretanto, de incentivar a frequencia aos cursos juridicos, concedendo vantagens a quantos fossem assiduos ás aulas, tais como: $a$ ) a de fazerem provas escritas, as duas provas parciais de cada ano e materia, sobre ponto sorteado "dentre os da parte explicada do programa"; $b$ ) a de fazerem prova oral de arguiçāo "sobre um ponto, tirado á sorte, dentre os do programa oficial da cadeira", mas somente dentre "os pontos que tiverem sido explicados durante o ano" E' o que está dito nos arts. 131, "a" e 135 e paragrafo primeiro do regulamento. Podem fazer exames na primeira época os alunos matriculados que bouverem assistido, no minimo, a dois terços das aulas dadas em cada 
cadeira e obtido, no minimo, nota cinco na média das provas parciais. Os que, todavia, não comparecerem ás aulas ou não tiverem o minimo de comparecimento estabelecido pela lei; ou os que, tendo sido assiduos, não tiverem alcançado a média, nas provas parciais - poderão fazer os seus exames na segunda época: na primeira quinzena de Fevereiro. Haverá, está escrito no art. 125 do regulamento, uma segunda época de provas, na primeira quinzena de Fevereiro, para os alunos: a) que não tenbam podido inscrever-se na primeira época; b) que, na primeira época, tenham sido aprovados em todas as cadeiras do ano, menos uma. E o art. 126 declarou que a inscrição para exames de segunda época "independe de ccrtidão de frequencia". Podem, consequentemente, faze-los, inscrevendo-se, os que deram mais de um terço de faltas ou os que nem mesmo a uma só aula assistiram, por mera curiosidade. E os exames, nos termos do art. 127, consistirão de uma prova escrita e prova oral, para cada cadeira, obedecidas, no aplicavel, as disposições relativas ás provas de primeira época, com as seguintes modificações: a) versará o exame sobre todos os pontos constantes do programa da cadeira; $b$ ) as notas das provas parciais porventura realizadas pelo aluno no ano anterior não serão computadas no julgamento. Previu a lei, portanto, a hipotese de não desejarem os alunos froquentar us cursos juridicos. Ou de não os poderem frequentar. A uns e outros permite realizem os seus exames na segunda época. A nenhum privou de oportunidade para a manifestação de seus conhecimentos juridicos; deixou a cada um a liberdade da escolha do sistema de exames de sua predileção ou de sua conveniencia.

\section{Ensino livre e semi-analfabetismo}

Se se insistir em adotar o regime da frequencia livre, o chamado. "ensino livre" entre nós já experimentado com tão singulares resultados, dever-se-á tambem, por coerencia, pugnar pela extinção da Universidade, recentemente criada e que foi o grande anhelo da mocidade de alguns anos atrás. Para que, com efeito, manter instituicões universitarias inocuas, sem cursos, sem aulas, sem disciplina e sem cultura? Pois já não atingiu a Camara dos Deputados a pretensão dos que tambem nāo desejam mais submeter-se a provas orais, que tantos talentos revelaram? Ainda bem que a Comissão de Educaçãu e Cultura deu parecer contrario ao projeto de as suprimir: oxalá não venha o plenario a rejeita-lo! Os exames por decreto já produziram os seus maleficos efeitos.

Moços matriculados nos cursos superiores, em numero surpreendente, são incapazes de escrever, sem erros gramaticais, as teses di- 
tadas para as provas escritas! U semi-analfabetismo é simplesmente alarmante. Convém denunciá-lo alto e bom som, para que se esboce contra êle reação energica e necessaria. Destacam-se muitos estudantes magnificamente preparados e dispostos a fazer o seu curso juridico com assiduidade e eficiencia. Constitue isso um suasissimo consolu. Serve, tambem, de demonstrar a possibilidade de um muvimento salutar em prol do ensino universitario. De outra fórma será mais logrico o fechamento das Faculdades. Fechar-se-ão. Abrir-se-ão, em lugar delas, repartições especiais para as matriculas, no começo de cada ano; e, quando Dezembro chegar, instalar-se-ão mesas especiais destinadas a dar ares de solenidade aos exames, transmudados em simples formalidade. Será isso mais simples. Mais facil. Mais comodo. E o que sera de maior circunstancia, muitissimo mais barato.

\section{O projeto Junqueira}

- E quanto aos efeitos do projeto Kibeiro Junqueira, no momento atual? Vem êle favorecer, realmente, a todos os estudantes de Direito?

- Não. Esse projeto estabelece o seguinte preceito:

"Nos cursos superiores, sem excepção, o aluno que obtiver média igual ou superior a seis, em qualquer cadeira, ficará dispensado, na referida cadeira, do exame final para promoção ao ano seguinte uu aprovação final.

A nota final de cada cadeira será a média aritmetica das provas parciais"

Ora, a esse respeito, são expressivos estes quadros:

PRIMEIRO ANO

$C A D E I R A S$

1.' 2 . $^{3}$

Não alcançaram a média cinco nas provas parciais, estando inhabilitados para a prova final

$85 \quad 39$

Tiveram cinco ou mais (5) a $51 / 2)$ e podem fazer exames finais

168114

Tivoram seis ou mais e podem prevalecer-se do fa-

vor do projeto Ribeiro Junqueira

84186

İao fizeram provas parciais

86

Total dos alumnos matriculados no primero ano 
SEGUNDO ANO

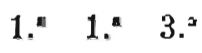

Não alcançaram a média cinco nas provas parciais, estando ihabilitados para a prova final

$24 \quad 12 \quad 11$

Tiveram cinco ou mais (5 a $51 / 2$ ) e podem fazer exames finais

Tiveram seis ou mais e podem prevalecer-se do favor do projeto Ribeiro Junqueira

Não fizeram provas parciais

Matricula cancelada

Total dos alunos matriculados no segundo ano

$112 \quad 140 \quad 98$

$\begin{array}{lll}7 & 7 & 6\end{array}$

$1 \quad 1 \quad 1$

$185185 \quad 185$

\section{TERCEIRO ANO}

Não alcançaram a média cinco nas provas parciais estando inhabilitados para a prova final

Tiveram cinco ou mais $(5$ a $51 / 2)$ e podem fazer exames finais

Tiveram seis ou mais e podem prevalecer-se do favor do projeto Ribeiro Junqueira

Não fizeram provas parciais

Total dos alunos matriculados no terceiro ano

$\begin{array}{lll}8 & 16 & 159\end{array}$

\section{1." 2." 3.'}

$\begin{array}{lll}8 & 38 & 59\end{array}$

$\begin{array}{lll}239 & 206 & 43\end{array}$

$\begin{array}{lll}18 & 13 & 12\end{array}$

$273 \quad 273 \quad 273$

\section{QUARTO ANO}

\section{2." $3 . .^{\text {a }} 4 . "$}

Não alcançaram a média cinco nas provas parciais, estando inhabilitados para a prova final

Tiveram cinco ou mais (5 a $51 / 2)$ e podem fazer exames finais

Tiveram seis ou mais e podem prevalecer-se do favor do projeto Ribeiro Junqueira

$\begin{array}{llll}186 & 144 & 99 & 159\end{array}$

Não fizeram provas parciais

Total ods alunos matriculados no quarto ano 256256256256 
Não obtiveram frequencia, não podendo inscrever-se para exames em 1." época:

\section{PRIMEIRO ANO}

1." cadeira - Introdução

47 alunos

2.* cadeira - Economia

78 "

SEGUNDO ANO

1." cadeira - Direito Civi]

$46 \quad "$

2." cadeira - Direito Penal

3.' cadeira - Direito Constitucional

56 "

$54 \quad "$

TERCEIRO ANO

1. cadeira - Direito Civil

$64 \quad "$

2." cadeira - Direito Penal

3.* cadeira - Direito Comercial

79 "

88 "

QCARTO ANO

1." cadeira - Direito Civil

2." cadeira - Dircito Comercial

3." cadeira - Direito Judiciario Civil

4." cadeira -- Medicina Legal

$\begin{aligned} 94 & \text { " } \\ 125 & \text { " } \\ 101 & \text { " } \\ 99 & \end{aligned}$

A primeira observação, que esses quadros sugerem, é a respeito do numero de estudantes matriculados na Faculdade de Direito, no ano letivo agora encerrado. Os que deviam receber agora o grau de bacharel, tiveram a sua laurea academica antecipada de um ano por um decreto ditatorial. Ainda assim, matricularam-se: no primeiro ano, 345 alunos; no segundo, 185 alunos; no terceiro, 273 alunos; e no quarto, 256 alunos. Ao todo, 1.059 alunos. Destes, a maior parte perdeu o ano, estando impossibilitada, pela lei, de fazer os seus exames na primeira época, por falta de assiduidade ás aulas. Varia de ano para ano do curso e de materia para materia o numero dos que não podem ser favorecidos pela munificencia da Camara dos Deputados, aprovando o projeto Ribeiro Junqueira.

Se ele fôr convertido em lei, ainda restará que a Côrte Suprema diga a ultima palavra sobre a sua inconstitucionalidade, que é manifesta...

- Acha que o projeto of ende a Constituição?

- Sem duvida. Nenhuma tenho eu quanto a isso. Pois êle não extingue, definitivamente, a prova oral final de cada ano. Deixa-a, em primeiro lugar, para os que nas parciais, tiveram cinco ou fração e não alcançaram seis; deixa-a, em segundo lugar, para os que dese- 
jarem fazê-la. Apenas dispensou dela os que tiverem média seis ou superior nas provas parciais. A prova oral, portanto, subsiste na lei e no regulamento. São dela dispensados alguns alunos, não todos. $\leftleftarrows \dot{e}$ isso, precisamente, o que o art. 158 da Constituição veda. Os estudantes, beneficiados pelo projeto Ribeiro Junqueira, que se acautelem: se a Côrte Suprema julgar constitucional a lei em que o projeto se converter, tudo estará bem. Na bipotese contraria, se a declaração da inconstitucionalidade vier antes de Fevereiro, eles poderão fazer os seus exames na segunda época; mas se vicr depois, êles terão que repetir o ano, o que será, não um presente de Natal, mas de grego...

\section{O CODIGO ELEITORAL E A CONSTITUIÇÃO}

Opinando no processo da representação dirigida ao Superior Tribunal Eleitoral, pelo Dr. João Mangabeira, sobre o sistema proporcional na eleição em face do que dispõe a Constituição Federal, o Dr. Sanpaio Doria, Procurador Geral junto áquele Tribunal, cmiliu o seguinte parecer:

“Não está em debate a adoção do sistema proporcional para as elcições de deputados e vereadores. Dispõe o art. 23 da Constituição:

"A Camara dos Deputados compõe-se de representantes do povo, eleitos mediante o sistema proporcional. "

E reitera o art. 181:

"As eleições para a composição da Camara dos Deputados, das Assembléias Legislativas Estaduais e das Camaras Municipais obedecerão ao sistema da representação proporcional.."

Nenhuma duvida, pois, sobre estatuir a Constituição que as eleicócs de Deputados e Vereadores no pais se devem processar pelo sistema proporcional.

Não é que a Constituição rejeite em toda a linha, o principio majoritario. Adotou-o para a eleição do Presidente da Republica e para a eleição dos Senadores. Adotou-o para o funcionamento da Camara dos Deputados e para as suas votações. Adopta-o da mesma forma para o Senado e para os Tribunais. E não poderia scr de outra forma.

Assente-se, pois, desde logo, esta premissa: em materia eleitoral, a Constituição prescreveu dois principios: o proporcional e o majoritario; aquele para as eleições de deputados e vereadores e este para as eleições do Presidente da Republica e de Senadores. 